\title{
Spatial Distribution and Determinant Factors of Anaemia Among Adults Aged 15-59 in Ethiopia; Using Mixed-effects Ordinal Logistic Regression Model
}

biruk tusa ( $\sim$ birukshalmeno27@gmail.com )

Haramaya University College of Health and Medical Sciences https://orcid.org/0000-0003-4362-0851

Sewnet Adem kebede

university of gondar

Adisu Birhanu Weldesenbet

Haramaya University College of Health and Medical Sciences

\section{Research}

Keywords: Anaemia, adults, spatial analysis, mixed-effects ordinal logistic regression, Ethiopia

Posted Date: August 7th, 2020

DOI: https://doi.org/10.21203/rs.3.rs-52531/v1

License: (c) (1) This work is licensed under a Creative Commons Attribution 4.0 International License.

Read Full License 


\section{Abstract}

Background: Anaemia is a global public health problem particularly in developing countries. Assessing the geographical distributions and determinant factors is a key and crucial step in designing targeted prevention and intervention programmes to address anaemia. Thus, the current study aimed to assess the spatial distribution and determinant factors of anaemia among adults aged 15-59 in Ethiopia.

Methods: A secondary data analysis was done based on 2016 Ethiopian Demographic and Health Surveys (EDHS). Total weighted samples of 29,140 adults were included. Data processing and analysis were performed using STATA 14; ArcGIS 10.1 and SaTScan 9.6 software. Spatial autocorrelation was checked using Global Moran's index (Moran's I). Hotspot analysis was made using Gettis-OrdGi*statistics. Additionally, spatial scan statistics were applied to identify significant primary and secondary cluster of anaemia. Mixed effect ordinal logistics were fitted to determine factors associated with the level of anaemia.

Result: The spatial distribution of anaemia among adults age 15-59 was found to be clustered in Ethiopia (Global Moran's I $=0.81, \mathrm{p}$ value $<0.0001$ ). In the multivariable mixed-effect

ordinal regression analysis; being females [AOR $=1.53 ; 95 \% \mathrm{Cl}: 1.42,1.66]$, never married $[\mathrm{AOR}=0.86$; $95 \% \mathrm{Cl}: 0.77,0.96]$, higher educated [AOR $=0.71 ; 95 \% \mathrm{Cl}: 0.60,0.84]$, rural residents [AOR $=1.53 ; 95 \% \mathrm{Cl}$ : $1.23,1.81]$, rich wealth status $[\mathrm{AOR}=0.77 ; 95 \% \mathrm{Cl}: 0.69,0.86]$ and underweight $[\mathrm{AOR}=1.15 ; 1.06,1.24]$ were significant predictors of anaemia among adults.

Conclusions: A significant clustering of anaemia among adults aged 15-59 were found in Ethiopia and the significant hotspot areas with high clusters of anaemia were identified in Somalia, Afar, Gambella, Dire Dewa and Harari regions. Besides, gender, marital status, educational level, place of residence, region, wealth index and body mass index (BMI) were significant predictors of anaemia. Therefore, effective public health intervention and nutritional education should be designed in the identified hotspot areas and risk groups to decrease the incidence of anaemia.

\section{Background}

Anaemia is a condition characterized by a low blood hemoglobin concentration (below $130 \mathrm{~g} / \mathrm{L}$ for men, $120 \mathrm{~g} / \mathrm{L}$ for non-pregnant women and below $110 \mathrm{~g} / \mathrm{L}$ in pregnant women). In such condition the oxygencarrying capacity of Red blood cells (RBCs) is insufficient to meet the physiological needs. It is a global public health problem particularly in low- and middle-income countries $(1,2)$.

Globally, over a quarter of the world population is affected by anaemia. Anaemia can affect the population of all age groups with the highest prevalence is in preschool-age children (47.4\%), the lowest prevalence is in men (12.7\%) and the greatest number of individuals affected among non-pregnant 
women (468.4 million) $(3,4)$.In Africa, prevalence rates of 16.8 to $33.8 \%$ among adults was reported from Uganda (5) whereas another study in South Africa (6) indicated anaemia prevalence is $12.5 \%$ in males and $13.2 \%$ in females. In Ethiopia, prevalence of $13 \%$ was reported among adults of both sexes (7).

Micronutrient deficiencies, parasitic infection, infectious diseases like TB, HIV, and maternal blood loss are common causes of anaemia in developing countries. The occurrence of the risk factors of anaemia concomitantly makes the efforts to single out a definitive cause challenging, especially in resource poor settings (8-10). Drug toxicity, deficiencies of iron, certain vitamins, copper, and protein are additional contributing factors for anaemia and Iron deficiency is the most common cause of anaemia responsible for $75 \%$ of anaemia cases (11).

Anaemia has large negative consequences on the health and economic wellbeing of nations and communities (12). In Ethiopia, despite the efforts to reduce anemia nationally, it is still an important public health problem and there is geographical variation (13). Assessing the geographic distributions of anemia and determinant factors are key and crucial step in designing targeted prevention and intervention programmes to address anaemia. Moreover, mapping the spatial distribution of anaemia prevalence by regions can help focus resources for prevention and treatment in the hot spot areas. Therefore, this study aimed to assess the spatial distribution and determinant factors of anaemia among adults aged 15-59 in Ethiopia using mixed-effect ordinal logistic regression.

\section{Methods}

\section{Data}

This study was a secondary data analysis based on 2016 Ethiopian Demographic and Health Surveys (EDHS). The 2016 EDHS was used a stratified two-stage cluster sampling techniquen using 2007 Population and Housing Census (PHC) as a sampling frame. Stratification was achieved by separating each region into urban and rural areas. Accordingly, a total, 21 sampling strata had been created.

In the first stage, 645 Enumeration Areas (EAs) (202 in urban areas and 443 in rural areas) were selected with probability proportional to the enumeration area size and with independent selection in each sampling stratum. At the second stage, since the time has passed since the PHC, a complete household listing operation was carried out in all selected EAs before the start of fieldwork and on average 28 households were systematically selected.

In the EDHS 2016, blood specimens for anaemia testing were collected from women and men that voluntarily consented to be tested. Blood samples were drawn from a drop of blood taken from a finger prick and collected in a micro cuvette. Hemoglobin analysis was carried out on site using a batteryoperated portable HemoCue analyzer. The detailed sampling procedure and the anaemia testing data (14) were presented in the full 2016 EDHS report. In the current study, total weighted samples of 29,140 adults were included. Latitude and longitude coordinates had been also taken from selected EAs (clusters). 


\section{Study variables}

The outcome variable for this study was hemoglobin level in the blood, a key indicator for anaemia. Hemoglobin levels (after adjusting for cigarette smoking and altitude in enumeration areas that are above 1,000 meters) in which women and men are considered not anaemic, mild, moderate and severe anaemic were presented in Table 1. Gender, age, marital status, educational level, place of residence, region, wealth index, source of drinking water, type of toilet facility, and Body Mass Index (BMI) were included as an independent variable in this study.

Table 1

Description of outcome variable used in the analysis

\begin{tabular}{|llll|}
\hline Anaemia levels & \multicolumn{3}{l|}{ Respondents (Hemoglobin level in g/dl) } \\
\cline { 2 - 4 } & Pregnant women & Non-pregnant women & Men \\
\hline Not anaemic & $\geq 11.0$ & $\geq 12.0$ & $\geq 13.0$ \\
\hline Mild & $10.0-10.9$ & $10.0-11.9$ & $10.0-12.9$ \\
\hline Moderate & $7.0-9.9$ & $7.0-9.9$ & $7.0-9.9$ \\
Severe & $<7.0$ & $<7.0$ & $<7.0$ \\
\hline
\end{tabular}

\section{Data source and extraction}

The data for this study was taken from the demography heath survey (DHS) program official database www.measuredhs.com, after authorization was granted through online request by explaining the goal of our study. We used the Personal Record (PR file) data set and extracted the outcome and independent variables.

\section{Data processing and management}

Data processing and analysis were performed using STATA 14; ArcGIS 10.1 and SaTScan 9.6 software. The data were weighted using sampling weight, primary sampling unit and strata before any statistical analysis to restore the representativeness of the survey and to tell the STATA to take into account the sampling design when calculating standard errors to get reliable statistical estimates. Cross tabulations and summary statistics were conducted to describe the study population.

\section{Spatial analysis}

\section{Spatial autocorrelation analysis}


The existence of spatial autocorrelation was checked using Global Moran's index (Moran's I). Global Moran's index (Moran's I) was used to identify the presence of spatial autocorrelation. Moran's I value ranges from- 1 to 1 (15). A value close to 1 indicates a strong positive spatial autocorrelation, whereas a value close to -1 indicates a strong negative spatial autocorrelation. If Moran's I close to 0 , it indicates that there is no spatial autocorrelation. A statistically significant Moran's I $(p<0.05)$ led to the rejection of the null hypothesis (anemia is randomly distributed) and showed the presence of spatial autocorrelation. Hotspot analysis was made using Gettis-OrdGi*statistics.

\section{Spatial scan statistical analysis}

Spatial scan statistics were applied to identify a significant primary (most likely) and secondary cluster of anemia using Kuldorff's SaTScan software. SaTScan ${ }^{T M}$ works with a moving window and requires fixing of the window size that moves across the study area. The outcome variable (anaemic and not anaemic) has a Bernoulli distribution so; the Bernoulli model was used by applying the Kulldorff method for purely spatial analysis.

Adults who were anaemic (mild, moderate, and severe) were taken as cases and those who were not anaemic were taken as controls to fit the Bernoulli model. The default maximum spatial cluster size of < $50 \%$ of the population was used as an upper limit, which allowed both small and large clusters to be detected and ignored clusters that contained more than the maximum limit. Areas with high Log Likelihood Ratio and significant p-value were considered as areas with high anaemic compared to areas outside of the window.

\section{Statistical analysis}

Since the EDHS data has a hierarchical nature, adults within a cluster may be more similar to each other than adults in the other cluster. Due to this, the assumption of independence of observations and equal variance across clusters might be violated. Therefore, an advanced statistical model is required to take into account the between cluster variability to get a reliable standard error and unbiased estimate.

Furthermore, by taking into account the ordinal nature of the outcome variable, ordinal logistic regression and mixed effect ordinal logistic were fitted. Model comparison was done based on Information Criteria. Mixed effect model with the lowest Information Criteria was selected (Table 2). Adjusted Odds Ratio (AOR) with a 95\% Confidence Interval $(\mathrm{Cl})$ and p-value 0.05 in the multivariable model were used to declare the determinant factors of anaemia. The assumption of proportional odds was checked and the results tell that the assumption of proportional odds is plausible at $5 \%$ level of significance for all considered covariates in the model. 
Table 2

Model comparison between ordinal logistic regression \& mixed effect ordinal logistic regression.

\begin{tabular}{|lll|}
\hline Proposed models & AIC value & BIC value \\
\hline Ordinal logistic regression & 30925.94 & 31229.31 \\
\hline Mixed effect ordinal logistic & 30543.93 & 30855.5 \\
\hline
\end{tabular}

AIC: Akaike Information Criteria; BIC: Bayesian Information Criteria

\section{Results}

\section{Characteristics of study population}

In this study, a total of weighted samples of 29,140 adults were included. Among this respondent, more than half $(53.04 \%)$ of them were females, more than one-third of them were uneducated $(38.51 \%), 34.94 \%$ were poor in wealth index and more than three fourth $(80.61 \%)$ of them were rural residents. Around 5,142 $(20.73 \%)$ of the study participants were in the age range of 15 to 19 years. Concerning the marital status, around 18,249 (62.62\%) respondents were married while 8,889 (30.51\%) respondents were never married. Near to one third $(35.98 \%)$ of the study participants were from Oromia region. Only $6.77 \%$ of the respondents had improved toilet facility, whereas near to two third $(64.50 \%)$ of study participants used improved drinking water. Regarding, the body mass index, more than one quarter $(26.44 \%)$ of the respondents were underweight (Table 3). 
Table 3

Characteristics of respondents in Ethiopia from January 18 to June 27, $2016(\mathrm{~N}=29,140)$

Variables

Anaemia level (weighted frequency)

Total

Percent

Not Mild Moderate Severe

anemic

Gender

Female

12,674

$2,050 \quad 626$

106

15,456

53.04

Male

11,847

$1,413 \quad 375$

49

13,684

46.96

Age

15-19

5,142

699

179

20

6,040

20.73

20-24

3,987

508

157

27

4,679

16.06

25-29

4,271

563

200

27

5,061

17.37

30-34

3,308

501

193

37

4,039

13.86

35-39

2,952

429

103

18

3,502

12.02

40-44

2,097

362

73

12

2,544

8.73

45-49

1,746

233

57

14

2,050

7.04

50-54

549

99

20

0

668

2.29

55-59

469

68

20

0

557

1.91

Marital status

Never married

7,752

$892 \quad 223$

22

8,889

30.51

Married

15,092

$2,329 \quad 712$

116

18,249

62.62

Widowed

424

70

19

6

520

1.78

Divorced

1,253

172

46

11

1,482

5.09

Educational level

Uneducated

$$
9,124
$$

1,498

490

109

11,221

38.51

Primary

10,426

$1,487 \quad 399$

36

12,348

42.37

Secondary

3,264

360

68

9

3,701

12.70

Higher

1,664

115

44

0

1,823

6.25

Don't know

44

3

0

0

47

0.16

Place of residence 


\begin{tabular}{|c|c|c|c|c|c|c|}
\hline Urban & 5,018 & 524 & 103 & 6 & 5,651 & 19.39 \\
\hline Rural & 19,503 & 2,940 & 897 & 149 & 23,489 & 80.61 \\
\hline \multicolumn{7}{|l|}{ Region } \\
\hline Tigray & 1,744 & 234 & 60 & 7 & 2,045 & 7.02 \\
\hline Afar & 141 & 44 & 20 & 2 & 207 & 0.71 \\
\hline Amhara & 6,920 & 779 & 136 & 11 & 7,846 & 26.92 \\
\hline Oromia & 8,593 & 1,379 & 432 & 80 & 10,484 & 35.98 \\
\hline Somali & 404 & 150 & 112 & 22 & 688 & 2.36 \\
\hline Benishangul & 243 & 28 & 7 & 0 & 278 & 0.95 \\
\hline SNNPR & 5,051 & 695 & 193 & 28 & 5,967 & 20.48 \\
\hline Gambella & 66 & 10 & 2 & 0 & 78 & 0.27 \\
\hline Harari & 43 & 7 & 3 & 1 & 54 & 0.18 \\
\hline Addis Ababa & 1,205 & 116 & 28 & 1 & 1,350 & 4.63 \\
\hline Dire Dawa & 113 & 21 & 8 & 1 & 143 & 0.49 \\
\hline \multicolumn{7}{|l|}{ Wealth index } \\
\hline Poor & 8,115 & 1,445 & 522 & 101 & 10,183 & 34.94 \\
\hline Middle & 4,863 & 689 & 190 & 12 & 5,754 & 19.74 \\
\hline Rich & 11,543 & 1,330 & 288 & 42 & 13,203 & 45.31 \\
\hline \multicolumn{7}{|l|}{$\begin{array}{l}\text { Source of drinking } \\
\text { water }\end{array}$} \\
\hline Improved & 16,142 & 2,071 & 528 & 54 & 18,795 & 64.50 \\
\hline Not improved & 8,379 & 1,392 & 473 & 101 & 10,345 & 35.50 \\
\hline \multicolumn{7}{|c|}{ Type of toilet facility } \\
\hline Improved & 1,710 & 209 & 50 & 3 & 1,972 & 6.77 \\
\hline Not improved & 22,811 & 3,254 & 951 & 152 & 27,168 & 93.23 \\
\hline \multicolumn{7}{|l|}{ BMI } \\
\hline Underweight & 6,390 & 963 & 300 & 52 & 7,705 & 26.44 \\
\hline Normal & 16,715 & 2,324 & 655 & 90 & 19,784 & 67.89 \\
\hline Overweight & 1,124 & 135 & 40 & 13 & 1,313 & 4.51 \\
\hline Obese & 292 & 41 & 5 & 1 & 339 & 1.16 \\
\hline
\end{tabular}




\section{Spatial analysis of anemia}

\section{Spatial distribution of anemia}

The spatial distribution of anaemia among adults aged 15-59 was identified to be clustered in Ethiopia (Global Moran's I $=0.81$, p value $<0.0001$ ) (Figure 1). The highest proportion of anaemia were found in the Somalia, Afar, and Gambella and regions, whereas low proportion of anemia was located in the Amhara, Tigray, northern part of SNNPR and Benishangul regions (Figure 2) .

\section{Gettis-OrdGi statistical analysis of anemia}

Based on the Gettis-OrdGi statistical analysis, this study identified hotspots and cold spot areas of anaemia among adults aged 15-59 in Ethiopia. Accordingly, the red colors indicate the significant hotspot area (higher cluster of anaemia), which were found in the Somalia, Afar, Gambella, Dire Dewa and Harari regions. In contrast, the blue color indicates significant cold spot areas (low cluster of anaemia), located in the Amhara, central Tigray and northern part of SNNPR and Benishangul regions (Figure 3).

\section{Spatial SaTScan analysis of anaemia (Bernoulli based model)}

A spatial scan statistical analysis recognized a total of 193 significant primary and secondary clusters. Among these, 192 clusters were primary (most likely) clusters which were located in the Somalia, Dire Dewa, Harari and eastern part of Oromia region at $5.589269 \mathrm{~N}$ and $44.175032 \mathrm{E}$, with $647.61 \mathrm{~km}$ radius, a Relative Risk (RR) of 1.89, and Log-Likelihood Ratio (LRR) of 237.90, at p-value $<0.01$ (Table 4). This told us that adults within the spatial window had 1.89 times higher risk of experiencing anaemia as compared to adults outside the spatial window. The secondary clusters were found in border areas between SNNPRs and Oromia regions (Figure 4). 
Table 4

Significant spatial clusters with high rate of Anaemia among adults age 15-59 in Ethiopia, 2016.

\begin{tabular}{|c|c|c|c|c|c|c|c|}
\hline Cluster & $\begin{array}{l}\text { Enumeration area (cluster) } \\
\text { identified }\end{array}$ & $\begin{array}{l}\text { Coordinate } \\
\text { (radius) }\end{array}$ & Population & Case & RR & LLR & $\begin{array}{l}\mathrm{P}- \\
\text { value }\end{array}$ \\
\hline 1 & $\begin{array}{l}138,164,85,358,146, \\
492,92,490,543,278, \\
171,198,95,318,77,187, \\
497,556,520,629,521, \\
588,553,458,480,208, \\
214,251,573,239,269, \\
116,22,394,378,630, \\
568,33,277,286,527, \\
289,64,439,57,186,8, \\
210,472,452,377,454, \\
513,436,501,212,68, \\
580,622,483,566,133, \\
587,194,240,500,321, \\
418,58,115,29,44,534, \\
179,257,387,157,397, \\
56,607,228,28,614,396, \\
60,393,357,419,443, \\
173,238,329,1,288,383, \\
495,381,610,473,372, \\
453,242,523,281,642, \\
166,311,307,30,557, \\
202,441,594,613,352, \\
74,519,380,535,273, \\
471,631,151,5,185,444, \\
111,514,282,27,390, \\
606,493,385,224,467, \\
644,43,363,190,546, \\
101,140,25,93,7,476, \\
412,529,245,123,333, \\
506,319,422,122,491 \\
562,213,34,71,82,518, \\
49,26,619,51,405,524, \\
230,564,468,576,313, \\
365,316,589,39,438, \\
601,149,398,336,12, \\
125,391,522,600,445 \\
578,484,135\end{array}$ & $\begin{array}{l}(5.589269 \\
\mathrm{N}, \\
44.175032 \\
\mathrm{E}) / \\
647.61 \mathrm{~km}\end{array}$ & 6265 & 1638 & 1.89 & 237.90 & $\begin{array}{l}< \\
0.001\end{array}$ \\
\hline 2 & 180 & $\begin{array}{l}(6.720108 \\
\mathrm{N}, \\
37.624880 \\
\mathrm{E}) / 0 \mathrm{~km}\end{array}$ & 113 & 45 & 2.56 & 19.19 & $\begin{array}{l}< \\
0.001\end{array}$ \\
\hline
\end{tabular}

LLR: Likelihood ratio; RR: Relative risk

\section{Determinant factors of anaemia}

Based on multivariable mixed-effects ordinal logistic regression model, gender, marital status, educational level, place of residence, region, wealth index and BMI were significantly associated with the 
level of anaemia among adults in Ethiopia at p-value 0.05 (Table 4).

The odds of female adult having severe anaemia (Compared to moderate, mild or non-anaemic) were 1.53 times higher than male adults while keeping other variables constant ( $\mathrm{OR}=1.53 ; 95 \% \mathrm{Cl}: 1.42,1.66)$. Making other variables constant, the likelihoods of never married adult experiencing severe anaemia (relative to moderate, mild or non-anaemic) were 0.86 times lower than married adults ( $O R=0.86 ; 95 \%$ Cl: $0.77,0.96)$.

Educational level was an important variable that showed significant association with level of anaemia among adults in Ethiopia. Holding other variables constant, the chances of uneducated adults developing severe anaemia (versus moderate, mild or non-anaemic) were $0.90,0.81,0.71$ times lower than primary, secondary and higher educated adults respectively.

The odds of rural adult experiencing severe anaemia (against moderate, mild or non-anaemic) were 1.53 times higher than urban adults while adjusting for other variables $(\mathrm{OR}=1.53 ; 95 \% \mathrm{Cl}: 1.23,1.81)$. Keeping other variables constant, the likelihoods of underweight adult having severe anaemia (opposed to moderate, mild or non-anaemic) were 1.15 times higher than normal adults $(\mathrm{OR}=1.15 ; 95 \% \mathrm{Cl}$ : 1.06 , 1.24).

The likelihoods of rich adult developing severe anaemia (compared to moderate, mild or non-anaemic) were 0.77 times lower than poor adults $(\mathrm{OR}=0.77 ; 95 \% \mathrm{Cl}: 0.69,0.86)$ while holding other variables constant.

Regarding region, adults residing in Afar, Somali, Harari and Dire Dawa were 1.68, 3.43, 1.48 and 2.04 times more likely to be severe anaemic (relative to moderate, mild or non-anaemic) than adults residing in Oromia respectively whereas the odds of severe anaemic (opposed to moderate, mild or non-anaemic) were decreased by $40 \%, 37 \%$ and $24 \%$ among adults residing in Amhara, Benishangul and SNNPR as compared with adult residing in Oromia respectively. 
Table 5

Bi-variable and multivariable mixed-effects ordinal logistic regression model of anaemia among adults age 15-59 in Ethiopia, 2016. $((\mathrm{N}=28,450))$

\begin{tabular}{|c|c|c|c|c|c|}
\hline \multirow[t]{2}{*}{ Variables } & \multicolumn{2}{|c|}{ Crude odds ratio } & \multicolumn{3}{|c|}{ Adjusted odds ratio } \\
\hline & OR & $95 \% \mathrm{Cl}$ & OR & $95 \% \mathrm{Cl}$ & P-value \\
\hline \multicolumn{6}{|l|}{ Gender } \\
\hline Male & Ref & Ref & Ref & Ref & Ref \\
\hline Female & 1.57 & {$[1.47,1.68]$} & 1.53 & {$[1.42,1.66]$} & $<0.001$ \\
\hline \multicolumn{6}{|l|}{ Age } \\
\hline $15-19$ & Ref & Ref & Ref & Ref & Ref \\
\hline $20-24$ & 1.01 & {$[0.90,1.12]$} & 0.96 & {$[0.85,1.08]$} & 0.49 \\
\hline $25-29$ & 1.12 & {$[1.01,1.25]$} & 1.04 & {$[0.91,1.18]$} & 0.59 \\
\hline $30-34$ & 1.28 & {$[1.14,1.43]$} & 1.12 & {$[0.97,1.29]$} & 0.12 \\
\hline $35-39$ & 1.15 & {$[1.02,1.29]$} & 1.01 & {$[0.86,1.17]$} & 0.95 \\
\hline $40-44$ & 1.16 & {$[1.02,1.32]$} & 1.03 & {$[0.88,1.21]$} & 0.70 \\
\hline $45-49$ & 1.02 & {$[0.88,1.18]$} & 0.91 & {$[0.76,1.08]$} & 0.29 \\
\hline $50-54$ & 0.99 & {$[0.78,1.24]$} & 1.13 & {$[0.87,1.46]$} & 0.37 \\
\hline $55-59$ & 1.06 & {$[0.82,1.37]$} & 1.18 & {$[0.89,1.57]$} & 0.26 \\
\hline \multicolumn{6}{|l|}{ Marital status } \\
\hline Married & Ref & Ref & Ref & Ref & Ref \\
\hline Never married & 0.74 & {$[0.69,0.80]$} & 0.86 & {$[0.77,0.96]$} & 0.01 \\
\hline Widowed & 1.13 & {$[0.91,1.40]$} & 0.99 & {$[0.80,1.24]$} & 0.98 \\
\hline Divorced & 1.02 & {$[0.88,1.17]$} & 0.96 & {$[0.83,1.11]$} & 0.62 \\
\hline \multicolumn{6}{|l|}{ Educational level } \\
\hline Uneducated & Ref & Ref & Ref & Ref & Ref \\
\hline Primary & 0.72 & {$[0.67,0.78]$} & 0.90 & {$[0.83,0.98]$} & 0.02 \\
\hline Secondary & 0.58 & {$[0.51,0.65]$} & 0.81 & {$[0.71,0.92]$} & 0.02 \\
\hline Higher & 0.47 & {$[0.40,0.55]$} & 0.71 & {$[0.60,0.84]$} & $<0.001$ \\
\hline Don't know & 0.33 & {$[0.12,0.95]$} & 0.46 & {$[0.16,1.32]$} & 0.15 \\
\hline Place of residence & & & & & \\
\hline
\end{tabular}




\begin{tabular}{|c|c|c|c|c|c|}
\hline Urban & Ref & Ref & Ref & Ref & Ref \\
\hline Rural & 1.93 & {$[1.64,0.27]$} & 1.53 & {$[1.23,1.81]$} & $<0.001$ \\
\hline \multicolumn{6}{|l|}{ Region } \\
\hline Oromia & Ref & Ref & Ref & Ref & Ref \\
\hline Tigray & 0.79 & {$[0.62,1.02]$} & 0.80 & {$[0.64,1.02]$} & 0.06 \\
\hline Afar & 2.38 & {$[1.84,3.09]$} & 2.04 & {$[1.61,2.59]$} & $<0.001$ \\
\hline Amhara & 0.61 & {$[0.47,0.77]$} & 0.60 & {$[0.48,0.76]$} & $<0.001$ \\
\hline Somali & 3.76 & {$[2.95,4.79]$} & 3.43 & {$[2.75,4.28]$} & $<0.001$ \\
\hline Benishangul & 0.66 & {$[0.50,0.87]$} & 0.63 & {$[0.49,0.81]$} & $<0.001$ \\
\hline SNNPR & 0.75 & {$[0.59,0.96]$} & 0.76 & {$[0.60,0.94]$} & 0.01 \\
\hline Gambella & 1.02 & {$[0.78,1.34]$} & 1.10 & {$[0.86,1.41]$} & 0.44 \\
\hline Harari & 1.13 & {$[0.85,1.51]$} & 1.48 & {$[1.13,1.93]$} & 0.01 \\
\hline Addis Ababa & 0.53 & {$[0.40,0.69]$} & 1.01 & {$[0.77,1.34]$} & 0.92 \\
\hline Dire Dawa & 1.18 & {$[0.89,1.56]$} & 1.68 & {$[1.28,2.19]$} & $<0.001$ \\
\hline \multicolumn{6}{|l|}{ Wealth index } \\
\hline Poor & Ref & Ref & Ref & Ref & Ref \\
\hline Middle & 0.811 & {$[0.73,0.91]$} & 0.92 & {$[0.83,1.03]$} & 0.17 \\
\hline Rich & 0.59 & {$[0.53,0.66]$} & 0.77 & {$[0.69,0.86]$} & $<0.001$ \\
\hline \multicolumn{6}{|c|}{ Source of drinking water } \\
\hline Not improved & Ref & Ref & Ref & Ref & Ref \\
\hline Improved & 0.87 & {$[0.80,0.96]$} & 1.05 & {$[0.96,1.14]$} & 0.32 \\
\hline \multicolumn{6}{|c|}{ Type of toilet facility } \\
\hline Not improved & Ref & Ref & Ref & Ref & Ref \\
\hline Improved & 0.94 & {$[0.84,1.07]$} & 1.01 & {$[0.90,1.15]$} & 0.81 \\
\hline \multicolumn{6}{|l|}{ BMI } \\
\hline Normal & Ref & Ref & Ref & Ref & Ref \\
\hline Underweight & 1.09 & {$[1.01,1.17]$} & 1.15 & {$[1.06,1.24]$} & $<0.001$ \\
\hline Overweight & 0.94 & {$[0.81,1.09]$} & 0.88 & {$[0.76,1.02]$} & 0.09 \\
\hline Obese & 0.99 & {$[0.77,1.27]$} & 0.88 & {$[0.68,1.14]$} & 0.33 \\
\hline
\end{tabular}




\begin{tabular}{|cccccc|}
\hline Cut1 & - & - & 2.05 & {$[1.76,2.34]$} & $<0.001$ \\
\hline Cut2 & - & - & 3.57 & {$[3.28,3.86]$} & $<0.001$ \\
\hline Cut3 & - & - & 5.70 & {$[5.39,6.03]$} & $<0.001$ \\
\hline Random intercept & & & & & \\
\hline $\operatorname{Var}($ cons) & - & - & 0.28 & {$[0.23,0.34]$} & - \\
\hline
\end{tabular}

AOR: Adjusted Odd ratio; COR: Crude Odd Ratio; Cl: Confidence interval; SNNPR: Southern Nation and Nationality and Peoples Regions

\section{Discussion}

This study was aimed to investigate the spatial distribution and determinants of anaemia among adults in Ethiopia. The spatial analysis result showed that the spatial distribution of anaemia among adults was significantly varied across the country. In multivariable mixed-effect ordinal regression analysis; gender, marital status, educational level, place of residence, region, wealth index and body mass index were significant predictors of the level of anaemia among adults in Ethiopia.

The present study documented that the spatial distribution of anaemia among adults was significantly varied across the country, where significant hotspot areas of anaemia were identified in the Somalia, Afar, Gambella, Dire Dewa and Harari regions. This spatial variation might be due to the difference in socioeconomic status, infectious disease risk (such as malaria, hookworm and etc.), dietary diversity and food security (16).

According to the current study, the odds of female adults having severe anaemia (Compared to moderate, mild or non-anaemic) were higher than male adults. This finding is in line with studies conducted in India (17) and United States of America (18). Such similar finding might be due to women experienced more blood loss through menstruation and greater demand on the blood supply for the developing fetus during pregnancy.

In agreement with another study (19), the current study revealed that the chances of uneducated adults developing severe anaemia (versus moderate, mild or non-anaemic) were higher than educated adults. The possible explanations for such results might be due to low socio-economic status, risky lifestyle and low diseases prevention knowledge and skilled among uneducated adults as compared to educated adults.

The present study documented that the odds of rural adults experiencing severe anaemia (against moderate, mild or non-anaemic) were higher than urban adults and this is of course congruent with other reports $(19,20)$. The possible reasons might be rural adults more likely to have low socioeconomic status, 
low chance of accessing iron-rich foods and lack of adequate nutrition information as compared to urban adults (19).

In line with other study (20), the present study reported that likelihoods of rich adult developing severe anaemia (compared to moderate, mild or non-anemic) were lower than poor adults. Such result indicates that poor adults have less access to nutritious food and fall sick more frequently as compared to the rich adults. This finding may not be surprising because keeping food security is a big issue among poor families (21).

According to the current study, the likelihoods of underweight adults having severe anaemia (opposed to moderate, mild or non-anaemic) were higher than normal adults. Even though a higher body mass index may not always show proper micronutrient consumption, an underweight $\left(\mathrm{BMl}<18.5 \mathrm{~g} / \mathrm{m}^{2}\right)$ person is more likely to have other concomitant comorbidity illness and scarce some essential micronutrients that may be related with anaemia (20).

The current study has some strengths and limitations that need to be in mind while interpreting the result. The first strength of the current study was using large population-based data with a large sample size, which is representative at national and regional levels, so it can be generalized to adult aged 15 to 59 in Ethiopia. Secondly, the combined use of both ArcGIS and Sat Scan statistical tests facilitated to identify similar and statistically significant areas with a high cluster of anaemia (hot spot area). Furthermore, by considering the ordinal nature of the outcome variable and cluster nature of data, the current study applies an advanced model (mixed effect ordinal logistic regression) to get reliable standard errors and parameter estimates.

The first limitation of the present study were the location of data values was displaced up to 2 kilometers for urban and up to 5 kilometers for rural areas to ensure respondent confidentiality, thus, this was the challenge to know the exact cases of ' location. Since the current study used secondary data, some important variable like dietary intake and presence of hookworm infection were not included in the analysis.

\section{Conclusion}

A significant clustering of anaemia among adults aged 15-59 was found in Ethiopia and the significant hotspot areas with high cluster anaemia were identified in Somalia, Afar, Gambella, Dire Dewa and Harari regions. Besides, gender, marital status, educational level, place of residence, region, wealth index and BMI were significant predictors of anaemia. Therefore, effective public health intervention and nutritional education should be designed in the identified hotspot areas and risk groups to decrease the incidence of anaemia.

\section{List Of Abbreviations}


AOR: Adjusted Odds Ratio; BMI: Body mass index; Cl: Confidence Interval; CSA: Central Statistics Agency; DHS: Demography heath survey; EAs: Enumeration Areas; EDHS: Ethiopian Demographic and Health Survey; SNNPR: Southern Nation and Nationality and Peoples Regions

\section{Declarations}

\section{Acknowledgments}

We would like to thank the measure DHS for providing us the data and shape files for the study area.

\section{Ethics approval and consent to participate}

The study does not contain the collection of information from subjects. We sent a one-page proposal abstract of the study to the DHS program office. They gave permission to access the data with a reference number of 144749 .

\section{Consent for publication}

Not applicable.

\section{Availability of data and materials}

All necessary information's and supplementary materials were included with the manuscript.

\section{Competing interest}

All authors declare no conflicts of interest.

\section{Funding}

No fund was received for this work.

\section{Authors' contributions}

Conception of the work, design of the work, acquisition of data, analysis, and interpretation of data were done by BS. Data curation, drafting the article, revising it critically for intellectual content, validation, and final approval of the version to be published were done by BS, SA and AB. All authors read and approved the final manuscript. 


\section{References}

1. Organization WH. Global technical strategy for malaria 2016-2030: World Health Organization; 2015.

2. Geneva S, Organization WH. Haemoglobin Concentrations for the Diagnosis of Anaemia and Assessment of Severity. Vitamin and Mineral Nutrition Information System. Document Reference WHO. NMH/NHD/MNM/11.1. http://www. who. int/entity/vmnis/indicators/haemoglobin ..., 2011.

3. Source WHOJR. Global anaemia prevalence and number of individuals affected. 2015.

4. Kassebaum NJ, Jasrasaria R, Naghavi M, Wulf SK, Johns N, Lozano R, et al. A systematic analysis of global anemia burden from 1990 to 2010. 2014;123(5):615-24.

5. Mugisha JO, Baisley K, Asiki G, Seeley J, Kuper HJPO. Prevalence, types, risk factors and clinical correlates of anaemia in older people in a rural Ugandan population. 2013;8(10):e78394.

6. Oldewage-Theron WH, Samuel F, Grobler C, Egal AJJoCS. Anaemia prevalence and dietary intake of elderly persons living in a peri-urban settlement in South Africa. 2008;36.

7. Mengesha MB, Dadi GBJBh. Prevalence of anemia among adults at Hawassa University referral hospital, Southern Ethiopia. 2019;19(1):1.

8. Yip R, Ramakrishnan UJTJon. Experiences and challenges in developing countries. 2002;132(4):827S-30S.

9. Petry N, Olofin I, Hurrell RF, Boy E, Wirth JP, Moursi M, et al. The proportion of anemia associated with iron deficiency in low, medium, and high human development index countries: a systematic analysis of national surveys. 2016;8(11):693.

10. Balarajan Y, Ramakrishnan U, Özaltin E, Shankar AH, Subramanian SJTI. Anaemia in low-income and middle-income countries. 2011;378(9809):2123-35.

11. Haidar JJJoh, population,, nutrition. Prevalence of anaemia, deficiencies of iron and folic acid and their determinants in Ethiopian women. 2010;28(4):359.

12. Walker SP, Wachs TD, Gardner JM, Lozoff B, Wasserman GA, Pollitt E, et al. Child development: risk factors for adverse outcomes in developing countries. 2007;369(9556):145-57.

13. CSA. Central Statistical Agency: Ethiopia demographic and health survey 2011. 2011.

14. Agency CS, ICF. Ethiopia Demographic and Health Survey 2016: Key Indicators Report. Addis Ababa, Ethiopia, and Rockville, Maryland, USA. CSA and ICF. 2016.

15. Waldhör T. The spatial autocorrelation coefficient Moran's I under heteroscedasticity. Statistics in Medicine. 1996;15(7-9):887-92.

16. Ejigu BA, Wencheko E, Berhane K. Spatial pattern and determinants of anaemia in Ethiopia. PLoS One. 2018;13(5):e0197171.

17. Little M, Zivot C, Humphries S, Dodd W, Patel K, Dewey C. Burden and Determinants of Anemia in a Rural Population in South India: A Cross-Sectional Study. Anemia. 2018;2018:7123976.

18. Le CHH. The prevalence of anemia and moderate-severe anemia in the US population (NHANES 2003-2012). PloS one. 2016;11(11):e0166635. 
19. Tesfaye TS, Tessema F, Jarso H. Prevalence of Anemia and Associated Factors Among "Apparently Healthy" Urban and Rural Residents in Ethiopia: A Comparative Cross-Sectional Study. Journal of Blood Medicine. 2020;11:89.

20. Adamu AL, Crampin A, Kayuni N, Amberbir A, Koole O, Phiri A, et al. Prevalence and risk factors for anemia severity and type in Malawian men and women: urban and rural differences. Popul Health Metr. 2017;15(1):12-.

21. Ajao K, Ojofeitimi E, Adebayo A, Fatusi A, Afolabi O. Influence of family size, household food security status, and child care practices on the nutritional status of under-five children in lle-lfe, Nigeria. African journal of reproductive health. 2010;14(4).

\section{Figures}

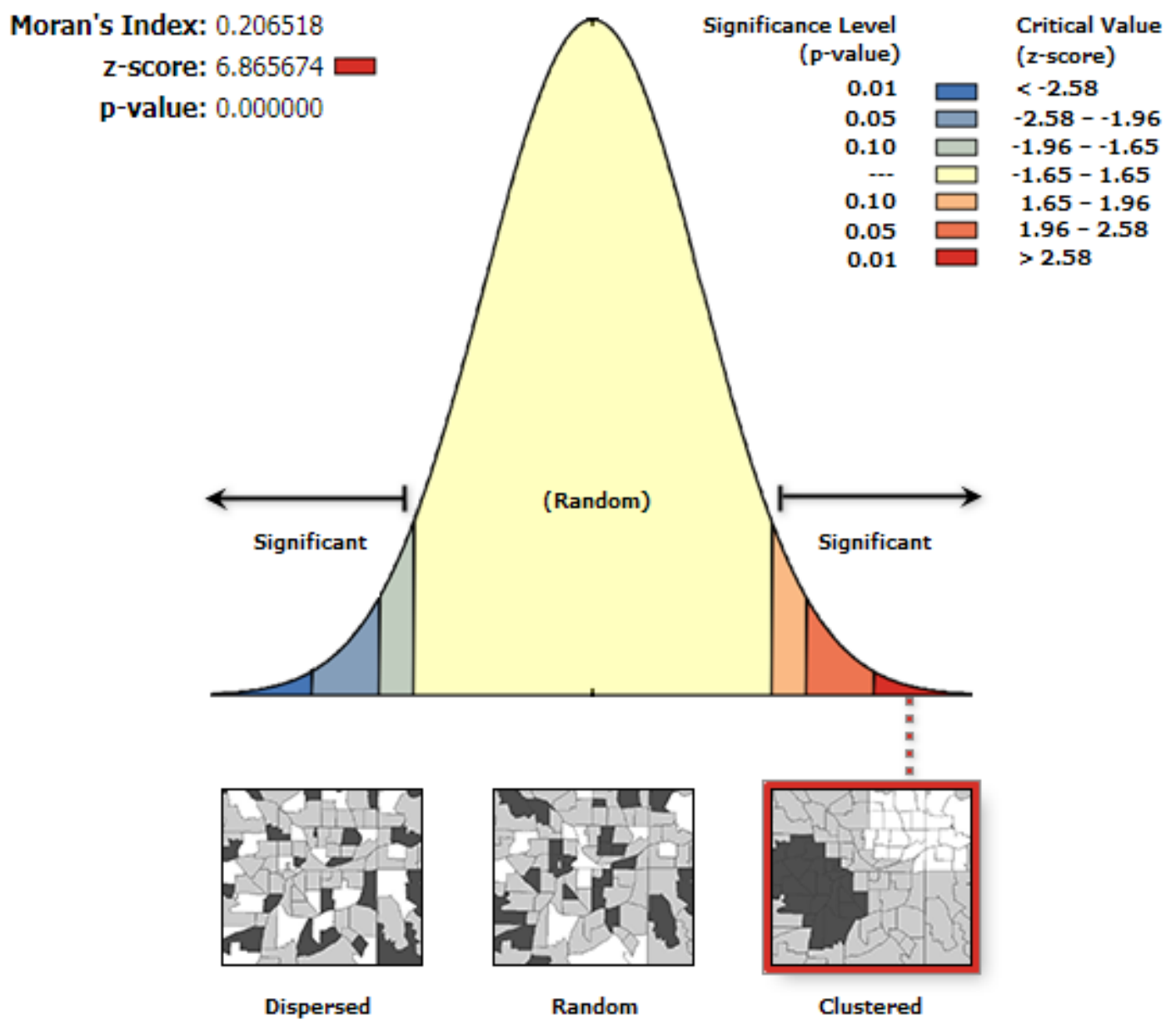

Figure 1

Spatial autocorrelation analysis of anaemia among adults aged 15-59 in Ethiopia, 2016 


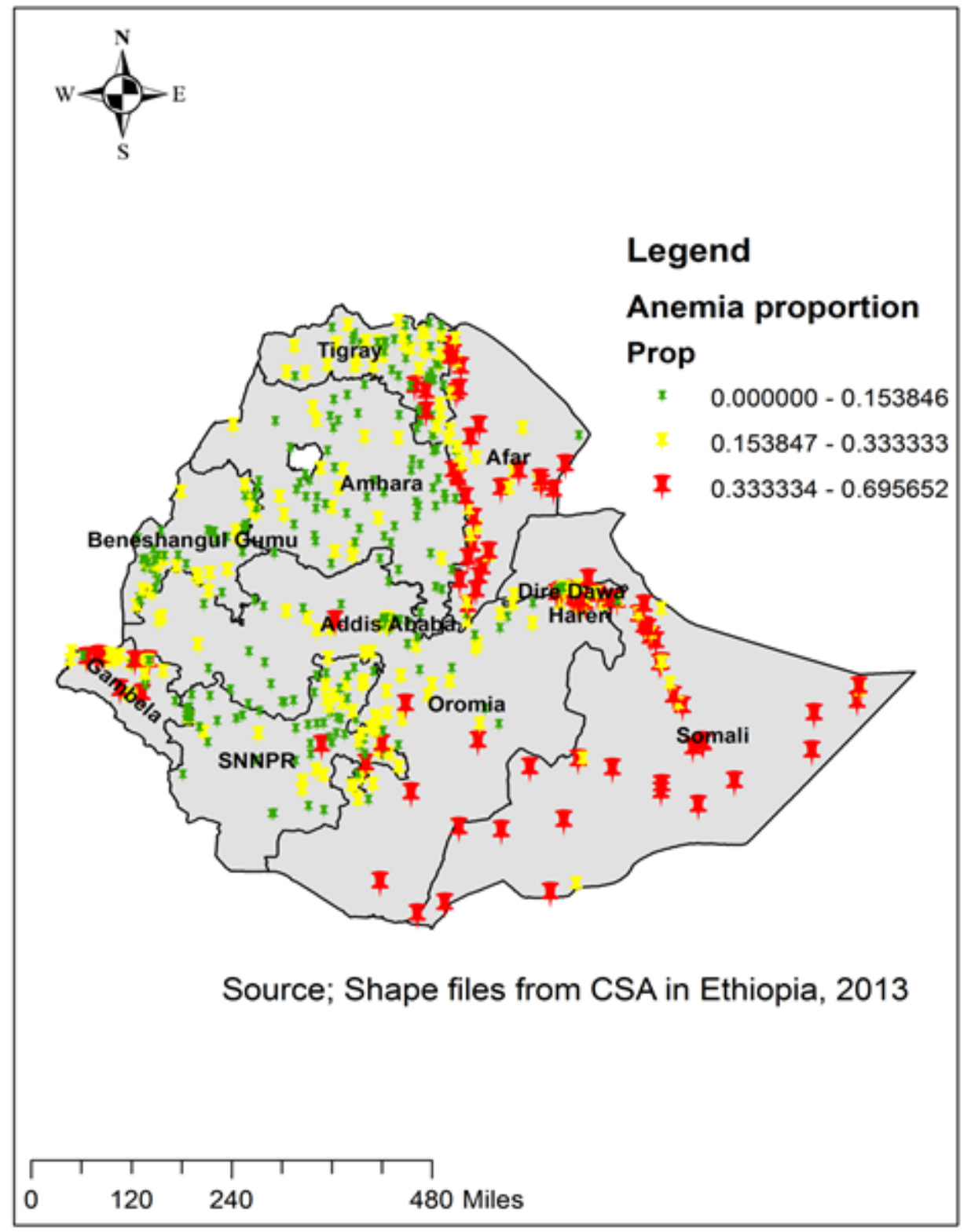

Figure 2

Spatial distribution of anaemia across regions among adults age 15-59 in Ethiopia, 2016 


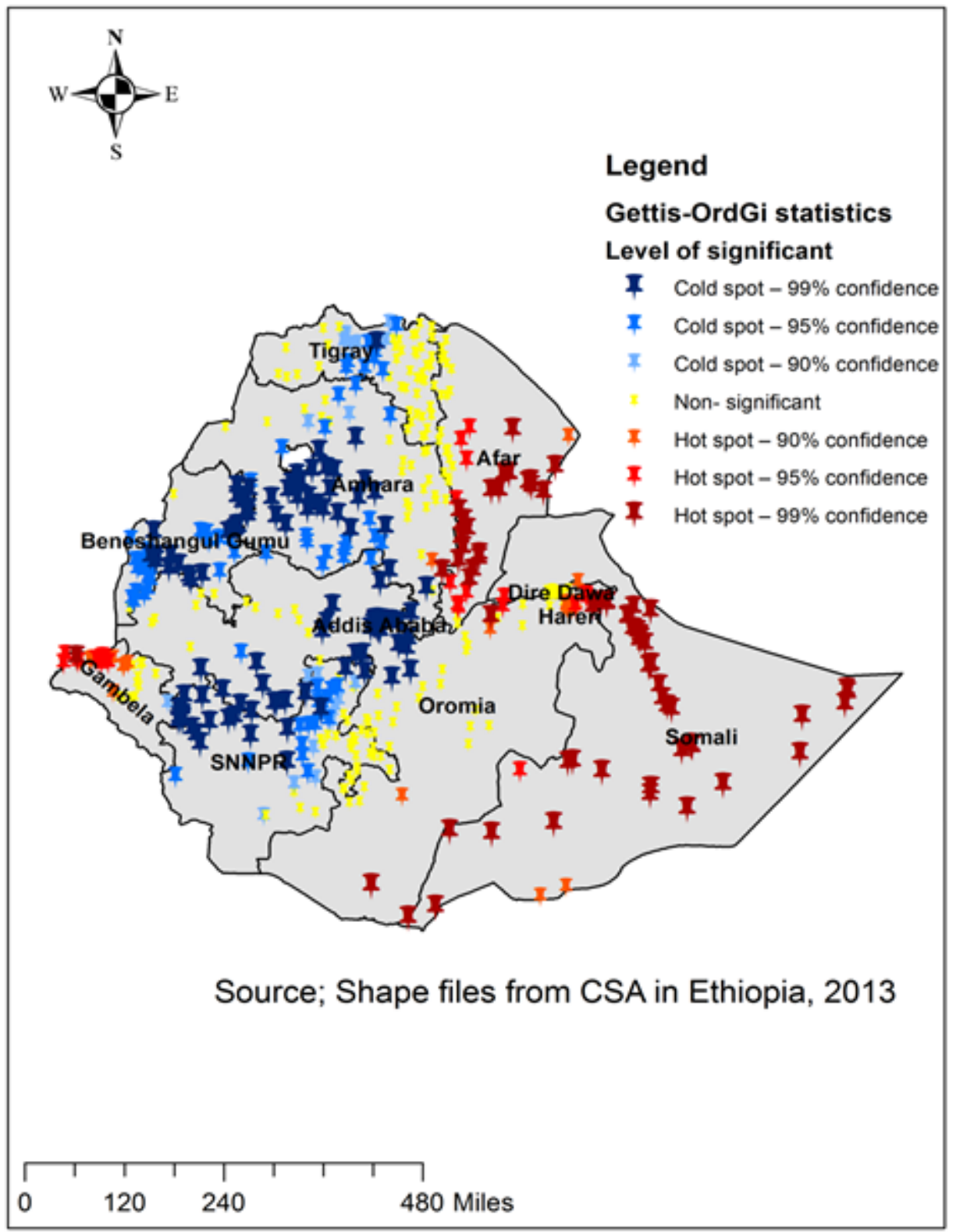

Figure 3

Hotspot and Cold areas anaemia across regions among adults age 15-59 in Ethiopia, 2016 


\section{Spatial scan statistics of anaemia in Ethiopia,2016}

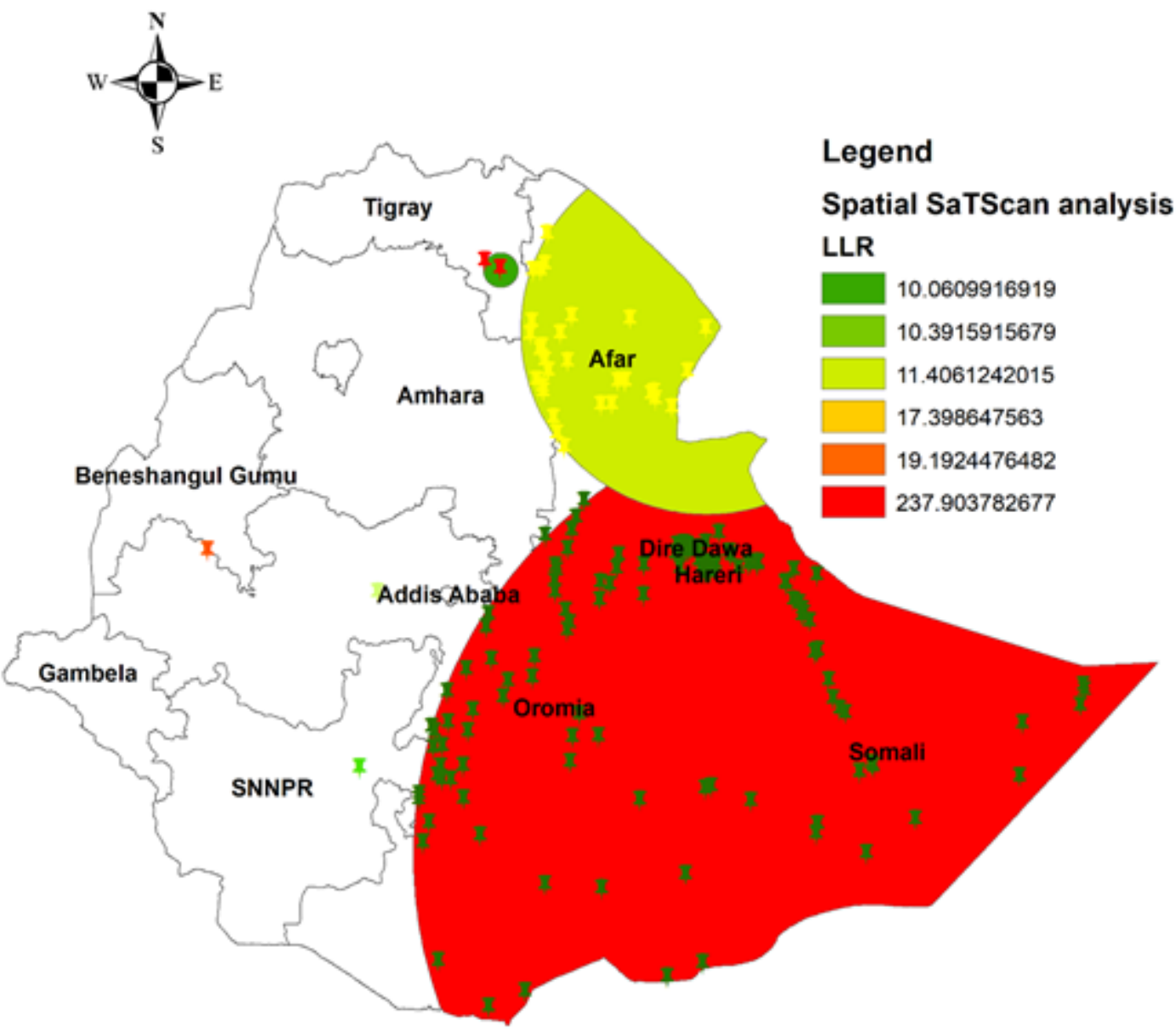

Source:Shape files from CSA in Ethiopia, 2013

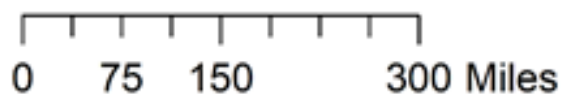

Figure 4

Primary and secondary clusters of Anaemia among adults age 15-59 in Ethiopia, 2016 